\title{
SURVEILLANCE OF SINO-NASAL ABNORMALITIES DIAGNOSED BY COMPUTED TOMOGRAPHY SCAN OF PARANASAL SINUSES IN A TEACHING HOSPITAL
}

\author{
Saumya Ranjan Das ${ }^{1}$, Ranjan Kumar Sahoo ${ }^{2}$ \\ ${ }^{1}$ Associate Professor, Department of ENT, Institute of Medical Sciences and SUM Hospital, Siksha O Anusandhan University, \\ Bhubaneswar, Odisha. \\ ${ }^{2}$ Assistant Professor, Department of Radiodiagnosis, Institute of Medical Sciences and SUM Hospital, Siksha O Anusandhan University, \\ Bhubaneswar, Odisha.
}

\section{ABSTRACT}

Computed tomography, CT scan of Paranasal Sinuses (PNS) is the gold standard test in diagnosing sinonasal abnormalities, which has the advantage of being able to show fine anatomic detail in serial tomographic sections, eliminating the gross volume averaging inherent in plain films.

AIM

To have surveillance of sinonasal abnormalities, from computed tomography CT scan of PNS, in the hospital in one year.

\section{MATERIAL AND METHODS}

Symptomatic patients pertaining to nose and paranasal sinuses were subjected to non-contrast CT scan of PNS by a GE Multidetector CT scan with $0.6 \mathrm{~mm}$ slices, for the diagnoses of sinonasal abnormalities from CT scan findings.

\section{RESULTS}

Of 339 patients, the primary radiological diagnoses were 66 Deviated Nasal Septum (DNS), 54 maxillary sinusitis, 47 ethmoid sinusitis, 44 Inferior Turbinate Hypertrophy (ITH), 35 maxillary sinus-mucosal hypertrophy, 28 frontal sinusitis, 20 ethmoidal polyp, 14 antrochoanal polyp, 12 nasal mass, 9 nasopharyngeal mass, 5 concha bullosa, 3 pan-sinusitis and 2 sphenoid sinusitis. There were 190 male and 149 female patients, diagnosed to have cited sinonasal diseases. The age distribution of diseases was: 57 in $\leq 14$ years (Paediatric), 155 in 15-39 years (Adults) and 127 in the age group of $\geq 40$ years (Elderly); 86 cases of sinusitis were associated with anatomical variants, among which deviated nasal septum and inferior turbinate hypertrophy were accountable for 31 cases each.

\section{CONCLUSION}

Deviated Nasal Septum (DNS) was the most frequently encountered condition in $19.5 \%$ of the total 339 patients. Among the patients of DNS, ITH was the most frequent co-existent abnormality. Maxillary sinusitis was the commonest sinus infection. Deviated nasal septum and inferior turbinate hypertrophy were most common anatomical variants seen in cases of sinusitis. CT scan of PNS is an indispensable diagnostic tool, which assisted in planning and advocating appropriate treatment modalities for sinonasal abnormalities.

\section{KEYWORDS}

Sinonasal Abnormalities; Computed Tomographic Scan.

HOW TO CITE THIS ARTICLE: Das SR, Sahoo RK. Surveillance of sinonasal abnormalities diagnosed by computed tomography scan of paranasal sinuses in a teaching hospital. J. Evolution Med. Dent. Sci. 2016;5(14):670-673, DOI: 10.14260/jemds/2016/153

\section{INTRODUCTION}

CT scan of PNS is the gold standard test in diagnosing sinonasal abnormalities. ${ }^{1}$ which has the advantage of being able to show fine anatomic detail in serial tomographic sections, eliminating the gross volume averaging inherent in plain films. Preoperative evaluation by CT scan has become mandatory for all patients, who are planned for Functional Endoscopic Sinus Surgery (FESS). ${ }^{2}$ while plain radiography was previously the most ordered study for the evaluation of sinonasal region, CT scan has surpassed it today, because of its greater anatomic precision required for endoscopic sinus surgery. ${ }^{3}$

Financial or Other, Competing Interest: None.

Submission 31-12-2015, Peer Review 29-01-2016,

Acceptance 03-02-2016, Published 18-02-2016.

Corresponding Author:

Dr. Saumya Ranjan Das,

Department of ENT,

Institute of Medical Sciences and SUM Hospital,

Siksha ' $O$ ' Anusandhan University,

K-8, Kalinga Nagar, Bhubaneswar-751003,

Odisha, India.

E-mail: saumya.ranjandas3@gmail.com

DOI: $10.14260 /$ jemds $/ 2016 / 153$
Indeed, CT scan PNS reinforces the clinical diagnosis in suspected sinonasal diseases in patients, as the confirmatory method to plan systematic medical and surgical treatment modalities. As the prevalence of incidental mucosal changes in asymptomatic population is about $30 \%$, CT scan PNS is valuable when interpreted in the context of the history and examination. ${ }^{4}$ The present study intends to analyse the prevalence of different abnormalities of nose and PNS diagnosed in patients undergoing CT scan PNS.

\section{MATERIAL AND METHODS}

Cases of 339 symptomatic patients referred to the Department of Radiodiagnosis from Otolaryngology and other clinical departments during 2014 for CT scan of the paranasal sinuses were considered for this study on sinonasal abnormalities.

Patients were subjected to non-contrast CT scan of PNS by a GE Multi-detector CT scan with $0.6 \mathrm{~mm}$ slices, for the diagnoses of sinonasal abnormalities from CT scan findings (Fig. 1). 


\section{RESULTS}

Of 339 patients, the primary diagnosed diseases along with their co-existent conditions were 66 Deviated Nasal Septum (DNS), 54 maxillary sinusitis, 47 ethmoid sinusitis, 44 Inferior Turbinate Hypertrophy (ITH), 35 maxillary sinus-mucosal hypertrophy, 28 frontal sinusitis, 20 ethmoidal polyp, 14 antrochoanal polyp, 12 nasal mass, 9 nasopharyngeal mass, 5 concha bullosa, 3 pansinusitis and 2 sphenoid sinusitis (Fig. 2). There were 190 male and 149 female patients, diagnosed to have cited sinonasal diseases. The age distribution of diseases was: 57 in $\leq 14$ years (Paediatric), 155 in 15-39 years (Adults) and 127 in the age group of $\geq 40$ years (Elderly); 207 patients were diagnosed with unilateral diseases, whereas 132 were with bilateral abnormalities. Altogether, different types of sinusitis were diagnosed as primary diseases in 169 of 339 patients (49.9\%), out of which 54 (32\%) cases were having maxillary sinusitis (Table 1). Among cases of sinusitis, 86 were found to have anatomical variants. Out of 86, 31 anatomical variants were DNS and 31 were ITH (Table 2).

\section{DISCUSSION}

As revealed in the present study, the most common diagnosed abnormality was DNS; seen in 66 of 339 patients (19.5\%). Inferior turbinate hypertrophy was the most frequent condition associated with DNS. Moreover among 66 patients with DNS, 29 were in the age group of 15-39 years, whereas 15 patients belonged to the paediatric age group. However, in a similar study, the prevalence of septal deviation in paediatric age group was $10.4 \% .{ }^{5}$ Prevalence rate of septal deviation in a radiological study was reported to be $24 \%$ of control populations. ${ }^{6}$ The incidence of septal deviation was more in males than females corroborating another study. ${ }^{7}$ Among the patients of DNS, ITH was the most frequent co-existent abnormality. In the present study, 54 of 339 patients (15.9\%) with sinonasal abnormalities were diagnosed as having maxillary sinusitis as the primary condition. This was a lower value than those recorded as prevalence of the maxillary sinusitis in asymptomatic subjects reported to be $30 \%$ of cases with the use of multiplanar images and $24.6 \%$ to $56.3 \%$ with Cone-Beam Computed Tomography (CBCT) studies reported elsewhere.8,9 In the present study, 169 (49.9\%) among 339 patients with primary sinonasal diagnoses were cases of sinusitis affecting different sinuses, moreover maxillary sinus was the most common sinus to be affected in 54 of 169 patients of sinusitis. This finding is comparable to that of a controlled series of biplane CT PNS, where the prevalence of asymptomatic sinus infection was $39 \% .{ }^{10}$ Sinus abnormalities in the present study were more frequently found in males, similar to the results reported in a study indicating that males were more vulnerable to the occurrence of mucosal thickening due to irritation of the sinus mucosa because of the greater prevalence of pathologic dental findings in them, as interpreted. ${ }^{11}$ As in another study isolated sphenoid sinus infection was less than $3 \%$ of the reported cases of sinusitis, which was frequently misdiagnosed due to vague symptoms and paucity of clinical findings. ${ }^{12}$ In the present study, isolated sphenoid sinusitis was encountered in 2 of 169 patients. Herein, among 34 patients having nasal polyps, 20 were diagnosed with ethmoid polyps, whereas 14 patients had antro-choanal polyps and it was seen as a male predominant disease. Moreover, ethmoid polyps were encountered most frequently in elderly patients, whereas antro-choanal polyps were commonly seen in the age group of 15 to 39 years. The prevalence of nasal polyposis as revealed in a study varied from 1 to $5 \%$, which were usually manifested after the age of 20 years; it was too a male predominating disease and the most common site of origination of nasal polyps was the anterior ethmoid region. ${ }^{13}$ As revealed in the present study, out of 86 cases of sinusitis having anatomical variants, DNS and ITH were most common anatomical variants. This finding is similar to that encountered in a study, in which DNS was the most common anatomical variant followed by agger nasi cells seen in $44 \%$ and $40 \%$ cases of sinusitis respectively. ${ }^{14}$

\section{CONCLUSION}

As revealed in the present study among patients having sinonasal diseases, which were more common in males, DNS was the most frequently diagnosed primary condition in $19.5 \%$ patients. Inferior turbinate hypertrophy was the most frequent condition associated with DNS. Maxillary sinusitis was the commonest sinus infection seen in 32\% among 169 primary diagnoses of sinusitis. Deviated nasal septum and inferior turbinate hypertrophy were most common anatomical variants seen in cases of sinusitis. CT scan of PNS is an indispensable diagnostic tool, which assisted in planning and advocating appropriate treatment modalities for sinonasal abnormalities.

\section{ACKNOWLEDGEMENT}

We are grateful to Dr. D.K. Roy, Medical Director and Mr. G. Kar, Managing Member, IMS and SUM Hospital for encouragements and facilities.

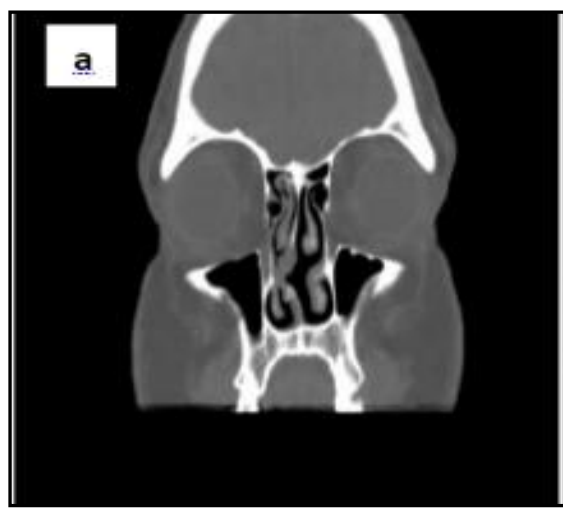

Fig. 1: CT scan PNS showing a;

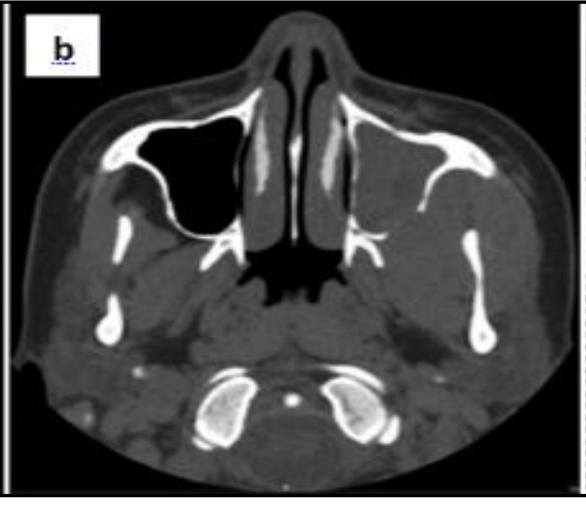

DNS, b; Maxillary sinusitis,

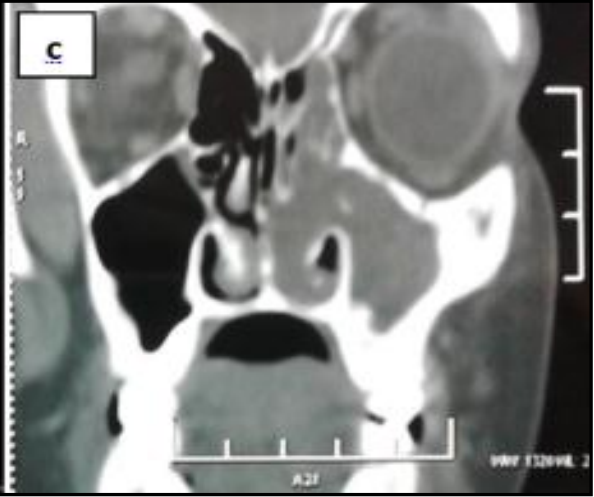

c; Antrochoanal polyp 


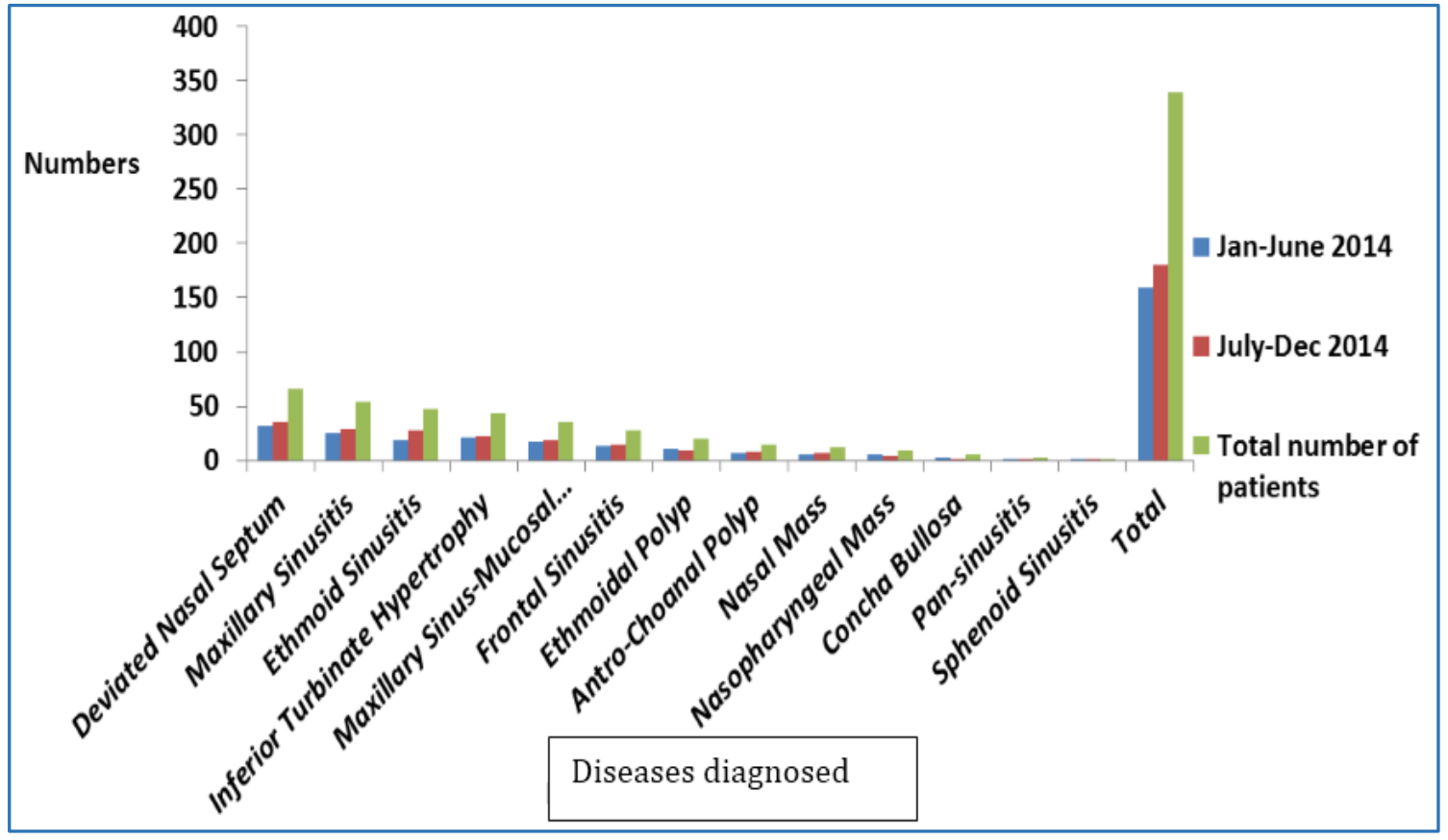

Fig. 2: Sinonasal diseases diagnosed by computed tomography scan of paranasal sinuses during one year

\begin{tabular}{|c|c|c|c|c|c|c|c|c|c|c|}
\hline \multicolumn{2}{|c|}{ Diagnosed Sinonasal Disease } & \multicolumn{3}{|c|}{ Age (Year) } & \multicolumn{2}{|c|}{ Sex } & \multicolumn{2}{|c|}{ Laterality } & \multirow{2}{*}{$\begin{array}{c}\text { No. of } \\
\text { Patients }\end{array}$} & \multirow{2}{*}{ Total } \\
\hline Primary Diagnosis & Co-existent Disease & $\leq 14$ & $15-39$ & $\geq 40$ & M & $\mathbf{F}$ & $\mathbf{U} / \mathbf{L}$ & B/L & & \\
\hline \multirow{8}{*}{$\begin{array}{l}\text { Deviated nasal } \\
\text { septum }\end{array}$} & ITH & 6 & 8 & 5 & 11 & 8 & 13 & 6 & 19 & \multirow{8}{*}{66} \\
\hline & ES & 3 & 5 & 4 & 7 & 5 & 8 & 4 & 12 & \\
\hline & MS & 1 & 4 & 5 & 5 & 5 & 6 & 4 & 10 & \\
\hline & CB & 2 & 3 & 3 & 6 & 2 & 5 & 3 & 8 & \\
\hline & FS & 1 & 3 & 1 & 3 & 2 & 4 & 1 & 5 & \\
\hline & MHMS & - & 1 & 2 & 1 & 2 & 2 & 1 & 3 & \\
\hline & SS & - & 1 & - & 1 & - & 1 & - & 1 & \\
\hline & NAD & 2 & 4 & 2 & 5 & 3 & 6 & 2 & 8 & \\
\hline \multirow{6}{*}{ Maxillary sinusitis } & ES & 3 & 10 & 6 & 11 & 8 & 13 & 6 & 19 & \multirow{6}{*}{54} \\
\hline & ITH & 2 & 6 & 4 & 7 & 5 & 8 & 4 & 12 & \\
\hline & FS & 2 & 4 & 3 & 5 & 4 & 6 & 3 & 9 & \\
\hline & SS & 1 & 3 & 2 & 3 & 3 & 2 & 4 & 6 & \\
\hline & $\mathrm{CB}$ & - & - & 1 & 1 & - & 1 & - & 1 & \\
\hline & NAD & 2 & 3 & 2 & 4 & 3 & 5 & 2 & 7 & \\
\hline \multirow{5}{*}{ Ethmoid sinusitis } & MHMS & 2 & 7 & 4 & 8 & 5 & 9 & 4 & 13 & \multirow{5}{*}{47} \\
\hline & ITH & 3 & 2 & 4 & 5 & 4 & 4 & 5 & 9 & \\
\hline & SS & 1 & 3 & 2 & 3 & 3 & 4 & 2 & 6 & \\
\hline & FS & 1 & 2 & 2 & 2 & 3 & 3 & 2 & 5 & \\
\hline & NAD & 2 & 8 & 4 & 9 & 5 & 8 & 6 & 14 & \\
\hline \multirow{4}{*}{ ITH } & $\mathrm{CB}$ & 1 & 5 & 3 & 5 & 4 & 6 & 3 & 9 & \multirow{4}{*}{44} \\
\hline & MHMS & 1 & 3 & 3 & 4 & 3 & 5 & 2 & 7 & \\
\hline & PS & - & - & 1 & 1 & - & - & 1 & 1 & \\
\hline & NAD & 5 & 13 & 9 & 16 & 11 & 10 & 17 & 27 & \\
\hline MHMS & NAD & 6 & 19 & 10 & 17 & 18 & 21 & 14 & 35 & 35 \\
\hline \multirow{3}{*}{ Frontal sinusitis } & ITH & - & 1 & 1 & 1 & 1 & - & 2 & 2 & \multirow{3}{*}{28} \\
\hline & $\mathrm{CB}$ & - & 1 & - & - & 1 & 1 & - & 1 & \\
\hline & NAD & 4 & 8 & 13 & 11 & 14 & 15 & 10 & 25 & \\
\hline Ethmoidal polyp & NAD & - & 9 & 11 & 11 & 9 & 2 & 18 & 20 & 20 \\
\hline ACP & NAD & 4 & 8 & 2 & 8 & 6 & 14 & - & 14 & 14 \\
\hline Nasal mass & NAD & 1 & 4 & 7 & 7 & 5 & 12 & - & 12 & 12 \\
\hline NP mass & NAD & - & 3 & 6 & 7 & 2 & 9 & - & 9 & 9 \\
\hline Concha bullosa & NAD & 1 & 2 & 2 & 2 & 3 & 3 & 2 & 5 & 5 \\
\hline Pan-sinusitis & NAD & - & 1 & 2 & 2 & 1 & - & 3 & 3 & 3 \\
\hline Sphenoid sinusitis & NAD & - & 1 & 1 & 1 & 1 & 1 & 1 & 2 & 2 \\
\hline \multicolumn{2}{|c|}{ Total } & 57 & 155 & 127 & 190 & 149 & 207 & 132 & 339 & 339 \\
\hline
\end{tabular}

Note: U/L, unilateral; B/L, bilateral; M, male; F, female; ITH, inferior turbinate hypertrophy; ES, ethmoid sinusitis; MS, maxillary sinusitis; CB, concha bullosa; FS, frontal sinusitis; MHMS, mucosal hypertrophy of maxillary sinus; SS, sphenoid sinusitis; NAD, no associated disease; PS, pan-sinusitis; ACP, antro-choanal polyp; NP, nasopharyngeal. 


\begin{tabular}{|c|c|c|c|c|c|c|}
\hline $\begin{array}{c}\text { Sinus- } \\
\text { Disease }\end{array}$ & $\begin{array}{c}\text { Deviated Nasal } \\
\text { Septum }\end{array}$ & $\begin{array}{c}\text { Inferior Turbinate } \\
\text { Hypertrophy }\end{array}$ & $\begin{array}{l}\text { Agger Nasi } \\
\text { Cells }\end{array}$ & $\begin{array}{c}\text { Paradoxical Middle } \\
\text { Turbinate }\end{array}$ & $\begin{array}{l}\text { Concha } \\
\text { Bullosa }\end{array}$ & Total \\
\hline $\begin{array}{l}\text { Maxillary } \\
\text { sinusitis }\end{array}$ & 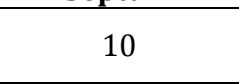 & 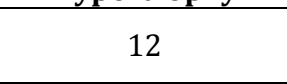 & 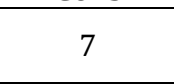 & 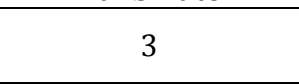 & 1 & 33 \\
\hline $\begin{array}{l}\text { Ethmoid } \\
\text { sinusitis }\end{array}$ & 12 & 9 & 5 & 1 & - & 27 \\
\hline MHMS & 3 & 7 & 2 & - & - & 12 \\
\hline $\begin{array}{c}\text { Frontal } \\
\text { sinusitis }\end{array}$ & 5 & 2 & 2 & 1 & 1 & 11 \\
\hline Pan-sinusitis & - & 1 & 1 & - & - & 2 \\
\hline $\begin{array}{c}\text { Sphenoid } \\
\text { sinusitis }\end{array}$ & 1 & - & - & - & - & 1 \\
\hline Total & 31 & 31 & 17 & 5 & 2 & 86 \\
\hline
\end{tabular}

Note: MHMS, mucosal hypertrophy of maxillary sinus.

\section{REFERENCES}

1. Hussein AO, Ahmed BH, Omer MAA, et al. Assessment of clinical X-ray and CT in diagnosis of paranasal sinus diseases. Int J of Sci Res 2014;3:7-11.

2. Dodd G, Jing B. Radiology of the nose, paranasal sinuses and nasopharynx. Baltimore: Williams \& Wilkins. 1977;5965.

3. Yousem DM. Imaging of sinonasal inflammatory disease. Radiology 1993;188:303-314.

4. Jones NS. CT of the paranasal sinuses: a review of the correlation with clinical, surgical and histopathological findings. Clin Otolaryngol All Sci 2002;27:11-17.

5. Lusk RP, McAlister B, Fouley A. Anatomic variation in paediatric chronic sinusitis. A CT Study. Oto Clin N Ame 1996;29:75-91.

6. Jones NS, Strobl A, Holland I. A study of the CT findings in 100 patients with rhinosinusitis and 100 controls. Clin Otoloaryngol All Sci 1997;22:47-51.

7. Nayak DR, Balakrishnan R, Deepak Murty $K$, et al. Endoscopic septoturbinoplasty: our update series. Ind J Otola Head Neck Surg 2002;54:20-24.
8. Diament MJ, Senac MOJR, Gilsanz V, et al. Prevalence of incidental paranasal sinuses opacification in paediatric patients: a CT study. J Comput Assist Tomogr 1987;11:426431.

9. Pazera P, Bornstein MM, Pazera A, et al. Incidental maxillary sinus findings in orthodontic patients: a radiographic analysis using cone-beam computed tomography (CBCT). Orthod Craniofac Res 2011;14:17-24.

10. Lloyd GAS. CT of the paranasal sinuses. Study of a controlled series in relation to endoscopic sinus surgery. J Laryngol Otol 1990;104:477-481.

11. Vallo J, Taipale LS, Huumonen S, et al. Prevalence of mucosal abnormalities of the maxillary sinus and their relationship to dental disease in panoramic radiography: results from the Health 2000 Hearth Examination Survey. Oral Surg, Oral Med, Oral Pathol, Oral Radiol Endod. 2010;109:80-87.

12. Lew D, Southwick FS, Montgomery WW, et al. Sphenoid sinusitis. A review of 30 cases. N Engl J Med 1983;309: 1149-1154.

13. Settipane GA. Epidemiology of nasal polyps. Allergy Asthma Proc 1996;17:231-236.

14. Dua K, Chopra H, Khurana AS, et al. CT scan variations in chronic sinusitis. Ind J Radiol Imag 2005;15:315-320. 